\title{
In Vitro and In Silico Liver Models: Current Trends, Challenges and Opportunities
}

\author{
Andrey Poloznikov 1,2,3, Irina Gazaryan 3,4,5, Maxim Shkurnikov 1, Sergey Nikulin 1,6, Oxana Drapkina , \\ Ancha Baranova 6,8,9 and Alexander Tonevitsky 10,11 \\ ${ }^{1}$ Hertsen Moscow Oncology Research Institute, Branch of the National Medical Research Radiological Center, Ministry of Health of the Russian \\ Federation, Moscow, Russia; ${ }^{2}$ Far Eastern Federal University, Vladivostok, Russia; ${ }^{3}$ Dmitry Rogachev National Medical Research Center of Pediatric \\ Hematology, Oncology and Immunology, Moscow, Russia; ${ }^{4}$ Department of Cell Biology and Anatomy, School of Medicine, New York Medical College, \\ Valhalla, NY, USA; ${ }^{5}$ Department of Chemistry and Physical Sciences, Dyson College, Pace University, Pleasantville, NY, USA; ${ }^{6}$ Moscow Institute of \\ Physics and Technology, Dolgoprudny, Moscow, Russia; ${ }^{7}$ National Research Center for Preventive Medicine of the Ministry of Healthcare of the Russian \\ Federation, Moscow, Russia; ${ }^{8}$ School of Systems Biology, George Mason University (GMU), Fairfax, VA, USA; ${ }^{9}$ Federal State Budgetary Institution \\ "Research Centre for Medical Genetics", Moscow, Russia; ${ }^{10}$ Higher School of Economics, Moscow, Russia; ${ }^{11}$ art photonics GmbH, Berlin, Germany
}

\begin{abstract}
Most common drug development failures originate from either bioavailability problems or unexpected toxic effects. The culprit is often the liver, which is responsible for biotransformation of the majority of xenobiotics. Liver may be modeled using liver-on-a-chip devices, which may include established cell lines, primary human cells, and stem cell-derived hepatocyte-like cells. The choice of biological material along with its processing and maintenance greatly influence both the device performance and the resultant toxicity predictions. Impediments to the development of liver-ona-chip technology include problems with standardization of cells, limitations imposed by culturing, and the necessity to develop more complicated fluidic contours. Recent breakthroughs in the development of cell-based reporters, including ones with fluorescent labels, permit monitoring of the behavior of the cells embedded into the liver-on-a-chip devices. Finally, a set of computational approaches has been developed to model both toxic responses and the homeostasis of human liver as a whole; these approaches pave the way to enhance the in silico assessment of potential toxicity.
\end{abstract}

\section{Introduction}

Drug development is becoming more and more expensive: It takes 12-15 years and around two billion dollars to bring a single drug into the market. The current paradigm of drug discovery relies on high throughput screening (HTS) of chemical libraries to identify compounds that bind purified target molecules produced by means of genetic engineering (Coussens et al., 2017; Raucy and Lasker, 2010). Lead compounds identified in HTS in vitro assays are subjected to secondary screens in established cell models before proceeding into animal testing. Currently, there is a substantial push for the development of standardized cell-based assays compatible with HTS format (Nickischer et al., 2018; Xia and Wong, 2012) or even the whole-animal assays (Delvecchio et al., 2011; O'Reilly et al., 2014; Pandey and Nichols, 2011).

Using human-derived cell line-based assays as the secondary screen has a number of advantages, the most important one being that cultivated cells are very close in their composition and metabolite concentrations to the cells in the human body. This characteristic helps to deprioritize drug candidates that are incapable of competing with endogenous co-substrates or co-ligands. Moreover, compounds that are unable to permeate cell membranes or that display direct toxicities would be also eliminated. However, work with the cell-line based models has a fundamental shortcoming: the human body is built from many hundreds of cell types, while commonly established cell cultures are typically homogenous.

One way to bridge this gap is to perform secondary screens in cell types representing the tissues most commonly contributing to the systemic toxicity that may arise when the whole body is exposed to a novel pharmaceutical. The culprit is often the liver, which is responsible for biotransformation of the majority of xenobiotics. Direct toxicity to the hepatic parenchyma is also quite common. Historically, approximately $20-30 \%$ of all drug withdrawals from US and EU markets are due to hepatotoxicity, with drug-induced liver injury (DILI) contributing at least $40 \%$ to the
Received March 22, 2018; Accepted May 22, 2018; Epub May 28, 2018; ( ) The Authors, 2018.

ALTEX 35(3), 397-412. doi:10.14573/altex.1803221

Correspondence: Ancha Baranova, PhD, School of Systems Biology,

College of Science, George Mason University,

Mail Stop 5B3, 10900 University Blvd, Manassas,

VA 20110-4400, USA

(abaranov@gmu.edu)
This is an Open Access article distributed under the terms of the Creative Commons Attribution 4.0 International license (http://creativecommons.org/licenses/by/4.0/) which permits unrestricted use, distribution and reproduction in any medium, provided the original work is appropriately cited. 
number of withdrawals in the United States (Olson et al., 2000; Peters, 2005). Ideally, potential drug toxicities should be discovered during preclinical testing in cellular or animal models. Nevertheless, many drugs were found to cause injury to human liver only after marketing and were subsequently either discontinued or received the warning label. Whether the failure of preclinical modeling is due to human genetic variants, immune reactions or disease-related metabolic problems, the animal models are limited in detecting human-specific phenomena. In addition, there is also a strong push to minimize the use of animal models due to ethical concerns (Langley et al., 2015).

Therefore, in this review we concentrate on liver cell-based platforms amenable to standardizing for their eventual use in toxicity screening compatible with HTS mode. This goal can be achieved with the development of liver-on-a-chip devices with embedded human cells. Such platforms may be useful both at the earliest steps of drug development (Fig. 1), which embraces the paradigm of "failing early-failing cheaply", and at later development stages, where they will eventually reduce the use of animals and provide more human-relevant information.

\section{Human liver metabolism differs from that of animals}

Liver is an intricate factory built by a variety of cooperating cells that perform over 500 distinct functions, including large scale synthesis of various blood components, metabolism of glucose, fatty acids and cholesterol, production of bile, and detoxification/ biotransformation of endogenous and exogenous substances. Of all the important liver functions, its metabolism - especially that of pharmaceutical drugs and other xenobiotics - is perhaps the most important in the context of pharmaceutical toxicology. In hepatic parenchyma, xenobiotics undergo three phases of metabolism and transport: (1) Phase I, which is mainly catalyzed by the cytochrome P450 enzymes (CYP450) and results in transformation of lipophilic compounds into water-soluble metabolites; (2) Phase II, where various enzymes conjugate xenobiotics and/ or their metabolites to highly polar molecules such as glucose, glucuronic acid, sulfate, or glutathione; (3) Phase III, where specific or non-specific transporters efflux these highly polar metabolites out of hepatocytes into the bile, or release them back to the blood for subsequent excretion with urine. The extreme diversity of the Phase I/II enzymatic system is a root cause for poor predictive performance of cell-based hepatotoxicity assays for possible adverse effects of potential drugs in humans.

Although Phase I reactions may be carried out by any combination of 50 cytochrome P450 (CYP450) monooxygenases, some of these enzymes are more important than others. Six cytochromes, namely CYP1A2, CYP2C9, CYP2C19, CYP2D6, CYP3A4, and CYP3A5, are capable of metabolizing 90\% of known drugs (Liddle and Stedman, 2007; Lynch and Price, 2007). Both the isoenzyme profile of these cytochromes and the relative catalytic activity within a particular source of the liver

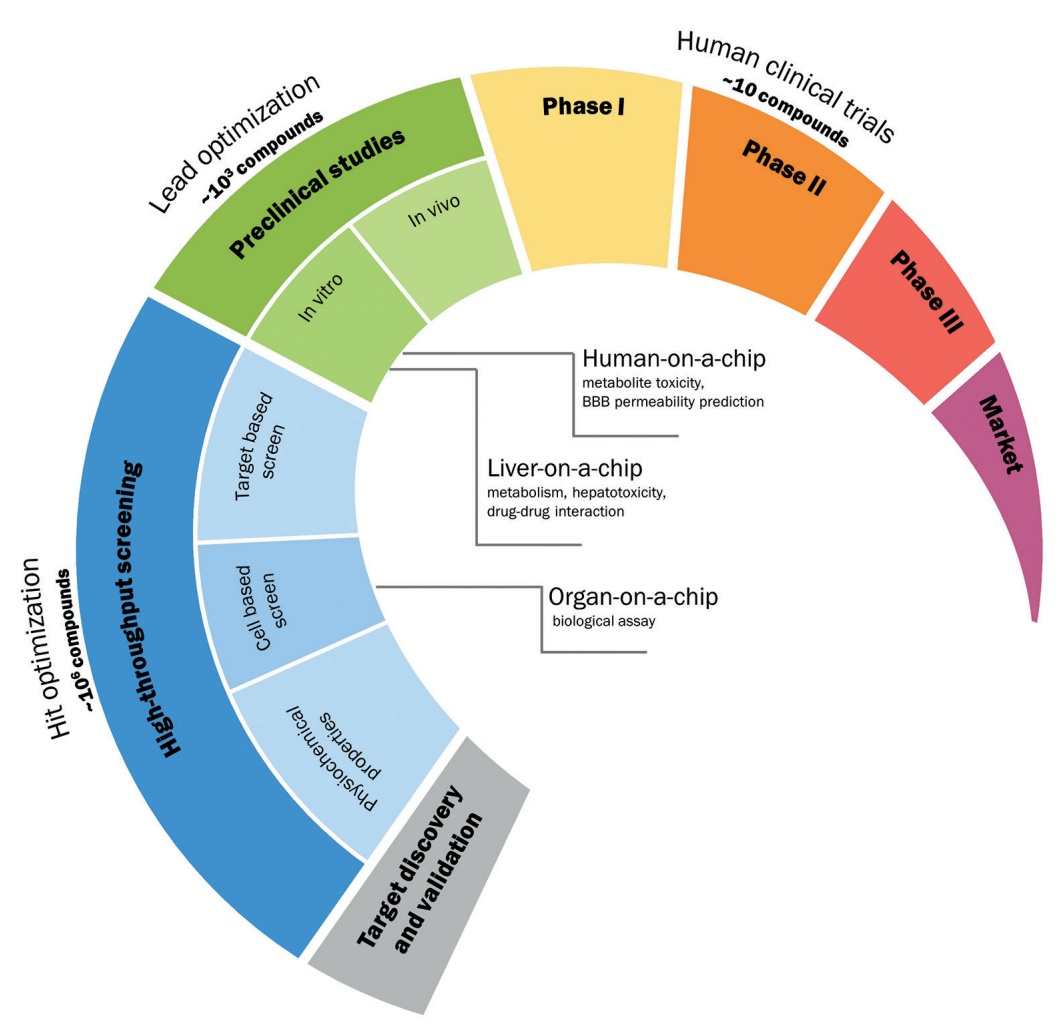

Fig. 1: HTS-based drug discovery paradigm 
Tab. 1: Comparison of cell sources for liver-on-a-chip technology

\begin{tabular}{|c|c|c|c|c|c|}
\hline $\begin{array}{l}\text { Cell source } \\
\text { (relevant } \\
\text { references) }\end{array}$ & $\begin{array}{l}\text { Primary } \\
\text { hepatocytes } \\
\text { (Bell et al., 2017; } \\
\text { Hart et al., 2010) }\end{array}$ & $\begin{array}{l}\text { Upcyte }^{\circledR} \\
\text { (Ramachandran } \\
\text { et al., 2015b; } \\
\text { Herzog et al., 2016; } \\
\text { Schaefer et al., } \\
\text { 2016, 2018) }\end{array}$ & $\begin{array}{l}\text { HepG2 } \\
\text { (Gerets et al., 2012; } \\
\text { Hart et al., 2010) }\end{array}$ & $\begin{array}{l}\text { Differentiated } \\
\text { HepaRG } \\
\text { (Bell et al., 2017; } \\
\text { Gerets et al., 2012; } \\
\text { Hart et al., 2010; } \\
\text { Le Vee M. et al., } \\
2006 \text { ) }\end{array}$ & $\begin{array}{l}\text { iPSC derived } \\
\text { (Baxter et al., } \\
\text { 2015; } \\
\text { Chaudhari et al., } \\
\text { 2016) }\end{array}$ \\
\hline $\begin{array}{l}\text { Genetic } \\
\text { similarity } \\
\text { to human } \\
\text { hepatocytes }\end{array}$ & $\begin{array}{l}\text { Exact (derived } \\
\text { from particular } \\
\text { individual) }\end{array}$ & $\begin{array}{l}\text { Exact (derived } \\
\text { from particular } \\
\text { individual) }\end{array}$ & $\begin{array}{l}\text { Medium } \\
\text { (derived from } \\
\text { hepatoblastoma } \\
\text { with abnormal } \\
\text { karyotype and } \\
\text { highly malignant } \\
\text { phenotype) }\end{array}$ & $\begin{array}{l}\text { High (quiescent, } \\
\text { differentiated } \\
\text { cancer cell line with } \\
\text { stable sub-diploid } \\
\text { karyotype with } \\
\text { minimal alterations) }\end{array}$ & $\begin{array}{l}\text { Exact (derived } \\
\text { from particular } \\
\text { individual) }\end{array}$ \\
\hline Variability & High & Low & High & Low & High \\
\hline Standardization & Impossible & Possible & Impossible & Possible & Impossible \\
\hline $\begin{array}{l}\text { Use in } \\
\text { personalized } \\
\text { medicine }\end{array}$ & Yes & No & No & No & Yes \\
\hline Supply & Limited & Unlimited & Unlimited & Relatively unlimited & Unlimited \\
\hline Viability & 10-14 days & 10-14 days & 7 days & 30 days & 2-4 days \\
\hline $\begin{array}{l}\text { Number of } \\
\text { passages }\end{array}$ & $\mathrm{n} / \mathrm{a}$ & 40 & Unlimited & $\begin{array}{l}20 \text { to preclude } \\
\text { instability }\end{array}$ & 50 \\
\hline $\begin{array}{l}\text { Functional } \\
\text { stability }\end{array}$ & Yes & Yes & No & Yes & Unknown \\
\hline $\begin{array}{l}\text { P450 enzymatic } \\
\text { profile }\end{array}$ & $\begin{array}{l}1 \mathrm{~A} 2,2 \mathrm{~A} 6,2 \mathrm{C} 8 \\
2 \mathrm{~B} 6,2 \mathrm{C} 19,2 \mathrm{C} 8 \\
2 \mathrm{D} 6,2 \mathrm{E} 1,2 \mathrm{C} 9 \\
3 \mathrm{~A} 4,3 \mathrm{~A} 5,3 \mathrm{~A} 7\end{array}$ & $\begin{array}{l}1 \mathrm{~A} 2,2 \mathrm{C} 8,2 \mathrm{~B} 6 \\
2 \mathrm{C} 19,2 \mathrm{C} 9,2 \mathrm{D} 6 \\
3 \mathrm{~A} 4\end{array}$ & $\begin{array}{l}1 \mathrm{~A} 2,2 \mathrm{C} 8,2 \mathrm{~B} 6 \\
2 \mathrm{C} 9,3 \mathrm{~A} 5,3 \mathrm{~A} 7\end{array}$ & $\begin{array}{l}1 \mathrm{~A} 2,2 \mathrm{~A} 6,2 \mathrm{~B} 6 \\
2 \mathrm{C} 19,2 \mathrm{C} 8,2 \mathrm{E} 1 \\
2 \mathrm{D} 6,2 \mathrm{C} 9,3 \mathrm{~A} 4 \\
3 \mathrm{~A} 5,3 \mathrm{~A} 7\end{array}$ & $\begin{array}{l}1 \mathrm{~A} 2,2 \mathrm{~A} 6,2 \mathrm{~B} 6 \\
2 \mathrm{C} 19,2 \mathrm{C} 8,2 \mathrm{E} 1 \\
2 \mathrm{D} 6,2 \mathrm{C} 9,3 \mathrm{~A} 4 \\
3 \mathrm{~A} 5,3 \mathrm{~A} 7\end{array}$ \\
\hline $\begin{array}{l}\text { Total P450 } \\
\text { activity }\end{array}$ & High & Low & Low & Medium & $\begin{array}{l}\text { Relatively low, as in } \\
\text { fetal hepatocytes }\end{array}$ \\
\hline Transporters & $\begin{array}{l}\text { ABCBA, ABCB7, } \\
\text { ABCF3, ABCB1, } \\
\text { ABCC1, ABCC2, } \\
\text { ABCC3, ABCE1, } \\
\text { ABCF1, ABCF2, } \\
\text { GTR1, SLCO1B1, } \\
\text { SLC22A1 }\end{array}$ & $\begin{array}{l}\text { ABCF3, ABCB1, } \\
\text { ABCC1, ABCC2, } \\
\text { ABCE1, ABCF1, } \\
\text { ABCF2, GTR1, } \\
\text { ABCB11, } \\
\text { SLCO1B1, } \\
\text { SLC22A1, } \\
\text { SLC47A1 }\end{array}$ & $\begin{array}{l}\text { ABCF3, ABCB1, } \\
\text { ABCC1, ABCE1, } \\
\text { ABCF1, ABCF2, } \\
\text { GTR1 }\end{array}$ & $\begin{array}{l}\text { ABCBA, ABCB7, } \\
\text { ABCF3, ABCB1, } \\
\text { ABCB11, ABCC1, } \\
\text { ABCC2, ABCC3, } \\
\text { ABCE1, ABCF1, } \\
\text { ABCF2, GTR1, } \\
\text { SLC22A1, } \\
\text { SLCO2B1, } \\
\text { SLCO1B1, } \\
\text { SLC10A1 }\end{array}$ & $\begin{array}{l}\text { ABCBA, ABCB7, } \\
\text { ABCF3, ABCB1, } \\
\text { ABCB11, ABCC1, } \\
\text { ABCC2, ABCE1, } \\
\text { ABCF1, ABCF2, } \\
\text { GTR1, SLC10A1 }\end{array}$ \\
\hline $\begin{array}{l}\text { Generation of } \\
\text { reporter lines }\end{array}$ & Impossible & Possible & Possible & $\begin{array}{l}\text { Possible with } \\
\text { limitations }\end{array}$ & Possible \\
\hline
\end{tabular}

material are most critical for the standardization and for proper functioning of the liver-on-a-chip device.

Phases I and II are commonly referred to as "metabolic detoxification," which is a misnomer, as many xenobiotics are metabolized into either bioactive or toxic compounds. Recapitulation of the in vitro liver drug metabolism is the pivotal aim of a liveron-a-chip development. Ideally, preclinical assays would require use of highly standardized cellular components; at the end, the potencies and other characteristics of various drugs should be compared one to another across the batches of disposable devices. The easiest way to standardize biological components of the chip without reverting to cell immortalization is to use cells prepared from inbred animals, for example, a particular strain of mice. Unfortunately, the comparison of the content of nine CYP450 enzymes in the microsomes derived from hepatic specimens procured from mouse, rat, rabbit, dog, micropig and monkey revealed that no single model species resembles the enzyme activities in human liver (Bogaards et al., 2000). More- 
over, the metabolic abilities of Phase II enzymes also markedly differ among species as was demonstrated for UDP-glucuronosyltransferase (UGT) activity (Hanioka et al., 2016) as well as for sulfation and glutathione conjugation (Miller et al., 1993).

Therefore, we would have to create liver chips using cells of human origin to best predict human liver metabolism. Let us consider how close different preparations of liver cells may resemble human liver (Tab. 1).

\section{Liver cells and cell lines: available choices}

Liver slices and whole perfused organs preserve an intact tissue structure, thereby being the most physiologically realistic model. However, their standardization and long-term maintenance have proven close to impossible. However, some reliable approximation of the liver could be achieved with the aid of microfabrication and advanced tissue engineering, capable of the generation of "on-a-chip" tissue and organ models suitable for HTS purposes. Of note, these models can be imaging- and analysis-friendly as they allow for real-time monitoring of the state of the living cells and their extracellular environment. A successful platform for mimicking liver physiology and hepatic drug metabolism in vitro is expected to replicate all major liver functions by controlling cellular dynamics over a prolonged period of time, which is currently defined as more than 28 days.

\subsection{Hepatocytes}

Human hepatocytes represent nearly $60 \%$ of the total cell population within the liver. These cells, capable of performing a majority of liver functions, can be isolated from the human liver via collagenase perfusion. Primary hepatocytes are commonly accepted as the "gold standard" for constructing liver models for drug testing and other applications. Maintaining an in vivo-like phenotype for isolated hepatocytes is challenging, since in a monolayer culture these cells undergo significant changes in Phase I and II metabolism and lose function over 72 hours (Rodriquez-Antona et al., 2002). Moreover, cultured primary hepatocytes may also lose their polarization, which would, in turn, greatly affect their ability to efflux biotransformed compounds (Luttringer et al., 2002; Noel et al., 2013). Luckily, both the widely used well-differentiated human hepatoma cell line HepaRG and primary human hepatocytes retain their polarization even in monolayers, as is evident by differential expression of a proper set of influx and efflux transporters at their sinusoidal and canalicular poles, respectively (Le Vee et al., 2013, 2015).

The functional life of hepatocytes may be prolonged by a variety of techniques. One promising approach is to culture them as spheroids, through inhibiting hepatocyte attachment to vessel walls and, thereby, enforcing their floating as aggregates. Spheroids may be formed by mechanical agitation by rotary shaker or spinner flask, hanging drop or using non-adherent surface chemistry. Hepatocellular spheroids retain a majority of the parenchymal functions, including the secretion of albumin, urea, transferrin and bile, along with Phase I and II biotransformation activity, for at least three weeks after seeding (Arakawa et al., 2017), which make them suitable for cytochrome induction tests. Hepatocyte spheroids are compatible with a serum-free medium and co-culturing with non-parenchymal Kupffer, stellate and biliary cells (Bell et al., 2016). Heterotypic spheroids reflect tissue environments in vivo, and, at least theoretically, permit construction of larger tissue models by higher order assembly of individual spheroids. In composite spheroids, i.e., spheroids composed of collagen microparticle scaffolds and cells, the optimal ratio of hepatocytes to type I collagen microparticles is approximately $1: 1$; the shift towards more of the collagen microparticles compromises hepatocyte functions (Yamada et al., 2015). On the other hand, an optimal co-culturing ratio for hepatocytes supported with endothelial progenitor cells is 5:1, in the presence of alginate-collagen (Chan et al., 2016). Another recent work used a $3 \mathrm{D}$ printing technique to combine alginate hydrogels with primary hepatocytes and mesenchymal stem cells (MSCs). This approach improved the viability of isolated hepatocytes to more than $90 \%$ and their morphological stability to up to 7 days (Kim et al., 2018).

Another hepatic modeling approach is based on sandwich cultures, also known as overlays. Sandwiching hepatocytes between two layers of ECM leads to formation of "plate" structures similar to the in vivo liver anatomy. The planar structure of the sandwich allows easy microscopic imaging. This technique preserves the polarity, including basal surfaces induced by ECM layers and apical surfaces by cell-to-cell contact, and leads to the development of a canalicular network and the secretion of bile (Swift et al., 2010). In sandwich cultures, the viable period may be increased to up to 6-8 weeks. However, sandwiched hepatocytes maintain their biotransformation activities and the ability to induce many Phase I and Phase II enzymes for the first two 2 weeks only.

Culturing primary hepatocytes within 3D structures formed by porous poly(L-lactide-co-glycolide) (PLGA) modified type I collagen nanofibers that mimic the natural liver environment is a promising strategy to improve the synthetic function of the liver cells over time (Brown et al., 2018).

In a recent study, primary human hepatocytes grown in a sandwich overlaid with extracellular matrix were directly compared to $3 \mathrm{D}$ spheroids in repeated-dose toxicity studies using 5 different liver toxins. To ensure robustness of the findings, the study was performed in six different laboratories using cryopreserved cells collected from the same set of donors. The study showed superiority of the 3D spheroids in expression of ADME-related proteins, as well as in catalytic activities of five different cytochromes (Bell et al., 2018).

\subsection{Upcyte ${ }^{\circledR}$ hepatocytes}

The upcyte ${ }^{\circledR}$ ("upregulated") technology involves virus-guided introduction of a unique combination of genes that induce and maintain cell proliferation until the cells reach confluence. This allows the primary cells to be passaged many times with the generation of billions of cells. Human upcyte ${ }^{\circledR}$ hepatocytes ${ }^{1}$ are primary human hepatocytes derived by transducing E6 and E7

1 http://www.upcyte.technologies.com 
proteins of human papillomaviruses, which release hepatocytes from cell cycle arrest and allow their proliferation in response to oncostatin M (OSM), a member of the interleukin-6 (IL-6) superfamily involved in liver regeneration. In cultures, upcyte ${ }^{\circledR}$ hepatocytes undergo a finite number of cell divisions without being immortalized or losing adult primary cell phenotype (Burkard et al., 2012). Upon stimulation with OSM, doubling time for these cells is between 33 and 49 hours. After OSM is withdrawn, upcyte ${ }^{\circledR}$ hepatocytes differentiate to generate highly functional cells. This method allows expanding human hepatocytes for 35 population doublings, resulting in $10^{15}$ (a quadrillion) cells from each liver biopsy. Over 12 billion upcyte $^{\circledR}$ hepatocytes can be generated from one vial of primary human hepatocytes, thus meeting the high demand for standardized cells necessary for HTS studies. In the first-generation upcyte ${ }^{\circledR}$ hepatocytes, cytochromes CYP1A2, CYP2B6, and CYP3A4, but not CYP2B6, were drug-inducible at the mRNA level, suggesting the necessity for additional optimization. Second-generation upcyte ${ }^{\circledR}$ hepatocytes (Levy et al., 2015) form metabolically functional, polarized cultures with functional bile canaliculi and expression profiles for nuclear receptors, Phase I and II enzymes, and drug transporter genes comparable to those in primary human hepatocytes. As with the first-generation upcyte $^{\circledR}$ hepatocytes, second-generation cells lack fetal markers and express cytokeratin 8 and 18, human serum albumin and store glycogen (Levy et al., 2015).

Upcyte $^{\circledR}$ technology opens new horizons in modeling organotypic cultures. In a recent report, functional $3 \mathrm{D}$ hepatic structures were generated using a defined mixture of three types of differentiated human upcyte ${ }^{\circledR}$ cells, namely hepatocytes, liver sinusoidal endothelial cells (LSECs) and mesenchymal stem cells (MSCs). When all three types of cells were plated on a thick layer of Matrigel ${ }^{\mathrm{TM}}$, they self-organized to form liver organoid-like structures within 24 hours; during a 10 day culturing in a bioreactor, these liver organoids showed typical functional characteristics of liver parenchyma including activity of CYP3A4, CYP2B6 and CYP2C9 as well as mRNA expression of several marker genes and other enzymes (Ramachandran et al., 2015a).

It is also important to note that upcyte ${ }^{\circledR}$ hepatocytes can be transformed with reporter constructs to permit real time monitoring of hepatocyte functions and/or drug effects.

\subsection{HepG2 cells}

The HepG2 cell line was derived from a hepatocellular carcinoma of a 15-year-old Caucasian male. Due to low endogenous expression of cytochromes, HepG2 cells are a relatively poor choice for detection of hepatotoxicity (Wilkening et al., 2003) (Tab. 1). Even when HepG2 cells are made to express cytochromes forcibly, via adenoviral transfection, these cells do not reach liver model standards, as they also lack activity of aldolase B; several drug transporters such as BSEP, OATP-C, NTCP, and OCT-1; and a range of non-cytochrome Phase II enzymes, such as GSTA 1/2 and GSTM1 (Gripon et al., 2002; Guillouzo et al., 2007; Wilkening et al., 2003).
Historically, HepG2 cells were extensively exploited to examine cytoprotective, antioxidative, hepatoprotective, anti-hepatoma, hypocholesterolemic, anti-steatosis, bioenergetic homeostatic and anti-insulin resistant properties of various bioactive compounds of chemical and botanical origin (Kaur et al., 2018). Due to high content of organelles and mtDNA, HepG2 cells remain a model of choice for investigation of mitochondrial toxicity through evaluations of mitochondrial fragmentation, lysosome content and mitophagy as well as mitochondrial release of cytochrome c, leading to apoptosis and/or necrosis (Paech et al., 2018; Paemanee et al., 2017). Because of that, attempts to improve the overall performance of HepG2 are continued, with the chief strategy to overcome their limitations being the development of three dimensional (3D) models, including co-culturing (He et al., 2018) and generation of the spheroids maintained in the hanging drops or otherwise (Hurrell et al., 2018; Shah et al., 2018).

\subsection{HepaRG cells}

Although the HepaRG cell line was derived from a hepatoma of a female patient with cirrhosis following hepatitis $\mathrm{C}$ virus infection (Gripon et al., 2002), unlike other human liver cell lines, HepaRG cells express many drug processing genes at levels similar to those in primary human hepatocytes. In particular, HepaRG express various nuclear receptors, transporters, and specific markers of adult hepatocytes (albumin, haptoglobins, and aldolase B) (Guillouzo et al., 2007). In confluent cultures, HepaRG cells differentiate from a stem cell/progenitor state to mature hepatocytes and primitive biliary cells and maintain a relatively stable function for several weeks (Jossé et al., 2008). HepaRG cells, including 3D-organotypic HepaRG cultures obtained using a scaffold-free, high-throughput hanging drop system are considered a viable option for evaluating hepatotoxic chemicals with reproducible responses (Gunness et al., 2013).

A high-throughput transcriptional profiling of both differentiated and undifferentiated HepaRG cells found that these cells have much higher resemblance to primary human hepatocytes and biopsied livers that HepG2 (Hart et al., 2010). These transcriptomics data have been recently supported by proteomics: a global proteomic analysis of HepG2, upcyte $^{\circledR}$, and HepaRG showed that the cytochrome activity levels of both HepG2 and upcyte $^{\circledR}$ were reduced by $90 \%$ in comparison to primary hepatocytes, while levels in HepaRG cells were reduced by $60 \%$ (Sison-Young et al., 2015). Remarkably, HepaRG cells also retained expression of MRP3 and P-gp (MDR1) transporters.

Molecular profiling data described above indicate that the HepaRG cell line in many ways resembles human primary hepatocytes, which is encouraging for utilization of these cells in the studies of xenobiotic metabolism, hepatotoxicology, and hepatocyte differentiation. It is, however, important to note that HepaRG cells eliminate galactose/sorbitol and produce albumin at rates higher than in primary hepatocytes, while being unable to excrete urea (Lübberstedt et al., 2011). As HepaRG cells are a clone derived from a particular individual, it is not surprising that the levels of cytochrome activities and their relative induc- 
ibility in these cells match some primary hepatocyte cultures but not others (Berger et al., 2016; Hart et al., 2010; Lübberstedt et al., 2011; Sison-Young et al., 2015). These differences are most likely intrinsic as they reflect variation in the expression levels of individual cytochromes across healthy humans.

\subsection{Induced pluripotent stem cells (iPSC)}

Induced pluripotent stem cell (iPSC) technology was introduced in 2006 (Takahashi and Yamanaka, 2006). iPSCs originate from adult cells reprogrammed by the introduction of several genes essential for embryonic stemness, namely Oct3/4, Sox2, c-Myc, and Klf4. Similar to embryonic stem cells, iPSCs can be differentiated into endoderm, mesoderm or ectoderm. This technology has important implications for drug toxicology (Anson et al., 2011). In particular, utilization of iPSCs in drug testing addresses the main problems arising from utilization of primary cells, such as limited quantities, donor to donor variation and relatively short lifespan in vitro, and circumvents ethical requirements since these cells do not come from embryos (Shafritz et al., 2009). iPSCs allow construction of surrogate liver panels to represent the most common combinations of Phase II enzyme variants and, therefore, to evaluate the potential of adverse drug reactions in the population and to provide an additional step towards the personalization of medicine. Thus, iPSCs may help to identify the potential for idiosyncratic hepatotoxicity, which may develop in some patients but not others - something which may be missed in the course of typical hepatotoxicity studies.

Since 2009, when the first protocol for the production of iPSC derived hepatocyte-like cells was published (Song et al., 2009), a variety of optimizing modifications to the standard procedure were proposed (Chen et al., 2012; Chin et al., 2009; Huang et al., 2014; Liu et al., 2010; Schwartz et al., 2014; Si-Tayeb et al., 2010; Takayama et al., 2012). Remarkably, some of these modifications simplified the workflow: instead of differentiating the cells in the presence of serum supplemented with growth factors and small metabolites, the protocols shifted towards greater standardization, with elimination of primary feeder cell requirements and introducing serum-free media.

iPSC-derived hepatocyte-like cells maintain a majority of hepatocytic functions, including the production of albumin, expression of cytochromes, and the storage of glycogen, while displaying global expression profiles resembling those of primary human hepatocytes (Gao and Liu, 2017). However, transcriptomic analyses revealed that for certain functional gene sets, the expression patterns of iPSC and of cultured primary hepatocytes differ substantially, with genes related to endocytosis upregulated (Bell et al., 2017), and cytochrome production downregulated (Bell et al., 2017; Si-Tayeb et al., 2010). Another aspect that limits wide utilization of iPSCs in drug testing is the standardization issue. The genetics of each iPSC line reflect the genetics of its donor. Consequently, iPSC lines differ in their epigenetic profiles, miRNA patterns and differentiation properties (Chin et al., 2009; Marchetto et al., 2009; Miura et al., 2009), which greatly contribute to lab-to-lab variations typically observed in toxicological studies. Furthermore, the efficiency of iPSC differentiation into hepatocytes is at $60 \%$ and even when best protocols are used (Chistiakov and Chistiakov, 2012) deriving the line requires expensive and time consuming extraction and purification steps.

To overcome the mentioned limitations, Cellular Dynamics International (CDI) has developed 95\% pure iPSC derived iCell ${ }^{\circledR}$ Hepatocytes, which are claimed to closely resemble primary cells. However, a recent comparative study of these cells along with HepaRG and human hepatocyte co-cultures showed that their metabolic activity is more than tenfold lower and approximates that of HepG2 (Kratochwil et al., 2017). This regretful outcome stresses the importance of keeping an eye on a "Holy Grail" of iPSC-based cellular modeling: a resemblance between the naturally differentiated cells residing within the body and forcefully differentiated cells produced from iPSCs.

One way to make sure that the produced cells perform adequately is to compare their expression profiles with those of naturally differentiated cells using CellNet, a computational platform which evaluates the extent to which cell- and tissue-specific gene regulatory networks are established under one or another differentiation protocol (Cahan et al., 2014; Radley et al., 2017). When correctly assessed for the resemblance of their target cell type, iPSC-derived hepatocyte-like cells may become a valuable tool for personalized toxicology and metabolism studies.

\section{Cell line standardization problem}

An induction of liver-on-a-chip technology into the main aisle of toxicology labs is critically dependent on our ability to standardize the cells seeded on to the chip. In principle, cell standardization requires the stability and reproducibility of the four main characteristics: (a) Viability for prolonged periods of time, which may be assessed via fluorescence imaging techniques that rely on a combination of nuclear and cytosolic dyes; (b) the retention of a toxicologically-relevant metabolic profile with stable activity of Phase I and Phase II enzymes; (c) drug transporter activity, which should be taken into consideration during initial vetting of an in vitro platform for studies of drug metabolism; (d) secretory capacity, which is approximated by albumin biosynthesis and urea excretion. Notably, a consistently high albumin production at levels of approximately $\sim 1-5 \mu \mathrm{g}$ per $10^{6}$ cells per hour serves as an indispensable indicator of the overall metabolic health of the cells; urea plays a similar role for evaluating general metabolic capacity. To directly detect albumin secreted by hepatocyte culture, 3D scaffold-based immunoassay chips have been developed recently (Yan et al., 2015).

As can be seen from Table 1, the standardization requirements are fulfilled only by upcyte ${ }^{\circledR}$ and HepaRG cells, with HepaRG being even closer in their cytochrome and transporter profiles to primary hepatocytes than the upcyte ${ }^{\circledR}$ cultures. To fully standardize the cell behavior in the liver-on-a-chip devices, there is a need to collect data to evaluate their response to exposure to a panel of at least 100 drugs, roughly divided into four categories that include safe and efficacious, safe and non-efficacious, non-safe and efficacious, and non-safe and non-efficacious compounds, all with well characterized in vivo metabolism. More- 
over, each drug has to be studied in a range of concentrations to determine both acute and chronic effects. In other words, both $\mathrm{IC}_{50} / \mathrm{LD}_{50}$ and a variety of the biomarkers of functional impairment have to be assessed.

\section{Limitations imposed by culturing}

Until recently, liver cell monocultures were a mainstay of toxicology practice for a number of well-defined "fit-for-purpose" assays. Nowadays, it is widely recognized that single cell type monolayers do not reflect the complexity of a tissue developed within a living organism. The limitations of hepatocyte monoculture are obvious. One of the most promising approaches to overcome the issues with viability of hepatocyte monoculture is the utilization of microfluidic perfusion devices (Knöspel et al., 2016; Shulman and Nahmias, 2013; Tehranirokh et al., 2013; Wagner et al., 2013). Unfortunately, for a majority of cell types, the cultivation period still does not exceed 14 days. Recently, Klein et al. (2014) demonstrated that HepaRG cells can be maintained in optimized serum-free media for 30 days without a decline in their viability. This finding certainly opens up the opportunity for the use of these cells in systems toxicology.

Both viability and functioning of hepatocytes are reduced in the absence of non-parenchymal cells. These supportive cells include fibroblasts, endothelial cells, stellate and Kupffer cells, and biliary epithelial cells (Ries et al., 2000; Soto-Gutierrez et al., 2010). Importantly, the addition of even one type of auxiliary cell often helps. For example, Okamoto et al. (1998) developed a co-culture system of primary human hepatocytes with the hepatic stellate cell line LI90, which retains a substantial activity of P450 cytochromes for at least 2 weeks, however, no rescue of urea excretion was noted. In another study, primary human hepatocytes were co-cultured with human umbilical vein endothelial cells (HUVEC) to achieve marked improvement of albumin production, urea biosynthesis and the rate of diazepam biotransformation (Salerno et al., 2011). Kostadinova et al. (2013) developed a 3D mixed culture of primary hepatocytes with a variety of non-parenchymal cell types. This liver-like culture maintained the production of albumin, fibrinogen, transferrin and urea for up to 3 months, while retaining the ability to induce the synthesis of cytochrome P450 on a drug exposure cue.

From the standpoint of liver biology, non-homotypic cultures have a better chance to correctly predict drug-induced liver injury as its development often depends on the communication between hepatocytes and the resident macrophages, which, upon exposure to certain drug metabolites, may be activated to serve as intrahepatic sources of inflammation (Endo et al., 2012; Kegel et al., 2015). Indeed, previously mentioned 3D liver equivalents containing a variety of non-parenchymal cells, including Kupffer macrophages, already demonstrated their value in the detection of potential inducers of idiosyncratic liver injury (Kostadinova et al., 2013). Similar results were obtained for micropatterned co-cultures containing either primary human hepatocytes or iPSC-derived hepatocytes and murine fibroblasts (Ware et al., 2015).
It is important to note that hepatocyte-produced drug metabolites may be non-toxic for liver cells while exerting adverse effects on other organs and tissues. To address this problem, several heterotypic cell cultures have been developed. For example, a microfluidic-based platform for co-culture of neurospheres and liver equivalents was recently employed in a two-week assay involving repeated exposure to the neurotoxin 2,5-hexanedione. It showed a significantly higher sensitivity compared to either hepatocyte or neurosphere monocultures (Materne et al., 2015). The same group also developed a platform for co-culture of liver organoids with skin (Wagner et al., 2013). On a microfluidic chip for the co-culture of HepaRG and kidney cells (MDCK) created by another group (Choucha-Snouber et al., 2013), a 3-day exposure to ifosfamide led to the detection of apparent nephrotoxic effects, while no toxicity was observed in monocultured MDCKs. In spheroid co-culture of HepaRG with primary human hepatic stellate cells (HSCs), exposure to pro-fibrotic compounds allowed the detection of multiple fibrotic features such as HSC activation, collagen secretion and deposition, thereby providing an avenue for in vitro testing of possible contributors to liver fibrosis (Leite et al., 2016).

\section{The way to improve hardware}

The need for better detection and instrumentation, as well as better materials, stems from the need to pump controlled microliter volumes of medium through the chip circuits and, in particular, to distribute the flow at critical junctions with a high degree of precision. Most scientists agree that devices of $100 \mu \mathrm{m}$ in height or less are preferable since at that scale they approach the diameter of the liver sinusoids, which is in the order of 5-10 $\mu \mathrm{m}$. At this height, the problems with the signal and/or metabolite dilution that plague larger-scale platforms are reduced.

Interpretation of the data generated with the aid of a microfluidic device critically depends on correct scaling of the physical and physiological parameters and on the relevance of the selected computational model of drug response and toxicity. One of the most important parameters that control the adsorption, distribution, metabolism, excretion and toxicity (ADMET) in physiological systems is the exposure time of the tissue to drugs and other xenobiotics, which is called the organ-specific transit time. According to an initial model generated in 1963 after experimentation on dogs, liver-specific transit time is between 10 and 20 seconds (Goresky, 1963). However, later studies demonstrated that in humans the hepatic transit time is substantially longer, from minutes to hours (Chiou, 1983). Moreover, hepatic transit time depends on the structure of a compound (Chiou, 1983) and may vary between individuals, being influenced by their genetics and overall state of health (Pedersen et al., 2005). Accordingly, to mimic in vivo ADMET characteristics in the fluidic systems, one has to have an ability to adjust fluidic residence times to the required physiological values.

To evaluate drug metabolite-induced toxicity, more complicated fluidic systems are necessary (Fig. 2) (Marx et al., 2016). Multi-parametric evaluation of the drug effects may include the 


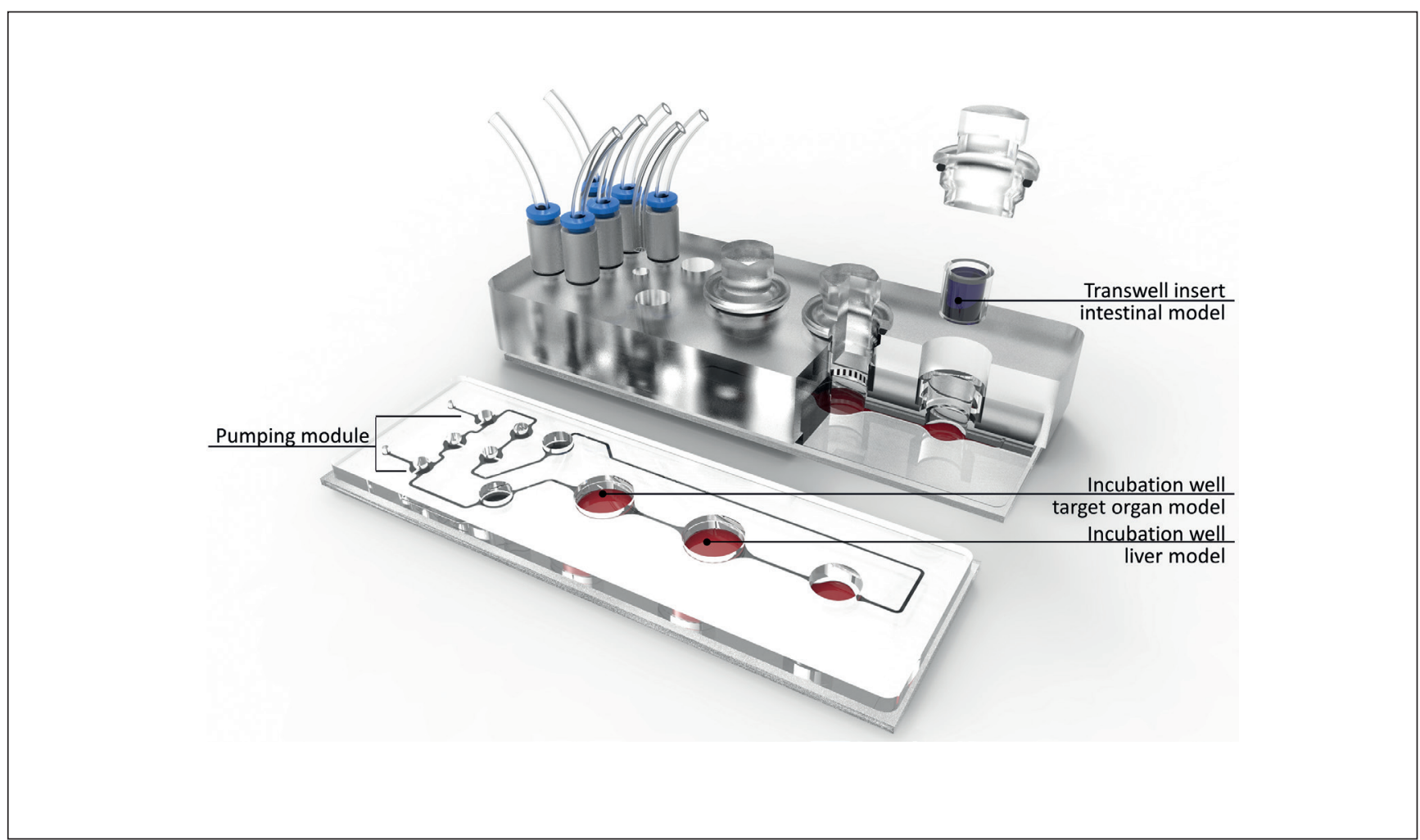

Fig. 2: Microfluidic platform for long-term multi-tissue coculture with closed circuit

studies of intestinal permeability, biotransformation pathways, as well as tests for the toxicity of a drug and its metabolites (Semenova et al., 2016; Zakhariants et al., 2016). Employing a combination of different cell types that reflect tissue-tissue interactions observed in whole organisms could significantly add to the value of the collected data. However, the disadvantages of multi-cell type devices stem from their underlying complexity and include low throughput and questionable scalability.

Detection in the microfluidic platforms is a challenge. In order to capture both acute and chronic effects of exposure to drugs, toxins or environmental factors, successful liver-on-a-chip devices should sum and present the data stream collected in real-time. On top of that, due to cell to cell differences observed in all types of culture, quantitative monitoring of intracellular changes and cell-cell interactions should be performed on a per cell basis, rather than in bulk. Growing trends of single-cell transcriptomics and biochip compatible reporters, are, in part, catering to this need.

One of the approaches to explore intracellular changes might be microRNA level monitoring in the culture medium of the microfluidic platform. MicroRNA (miRNA) is a class of small non-coding RNAs that mediate post-transcriptional gene silencing by sequence-specific inhibition of the target mRNAs' translation and/or lowering their half-lives in the cytoplasm (Turchinovich et al., 2015, 2016). Together with their binding partners, Argonaute proteins, miRNAs form cores of RNA-induced silencing complexes. Finally, the discovery of cell-free
miRNAs in all biological fluids suggests that miRNAs might also act as signaling molecules outside the cell, and may be utilized as biomarkers (Makarova et al., 2014, 2016).

To monitor the state of the hepatocyte cell culture, both hepatocyte-specific microRNAs (miR-122) and miRNA species highly expressed in the liver (miR-21, miR-19a/b, miR-106a/b) may be employed. The change in the representation of these microRNAs in the culture medium may be utilized for sensing a physiological change in the hepatocytes under the influence of the studied compound. Also, a number of microRNAs affecting the expression of ADMET genes were discovered. So, for example, miR-27b and miR-378 (Mohri et al., 2010) regulate the expression of cytochromes 1B1, 2E1 and 3A4. The appearance of such microRNAs in the microfluidic system cell culture medium may thus significantly affect the functional capacity of the device.

Metabolomics presents yet another, very interesting alternative for extracting quantitative information about the dynamic metabolic response of the modelled liver to pathophysiological conditions. In two recent studies, the metabolite profiles of HepG2 cells treated with various test substances were analyzed to reveal concentration-response effects mapped to a variety of the response patterns consistent with different liver toxicity mechanisms (García-Cañaveras et al., 2016; Ramirez et al., 2018).

On the other hand, the spatiotemporal dynamics of the multicellular milieu could be monitored with the aid of a small fluorescent molecule (probe) or a protein-based fluorescent biosensor. In this respect, reporter cells have great promise; such 


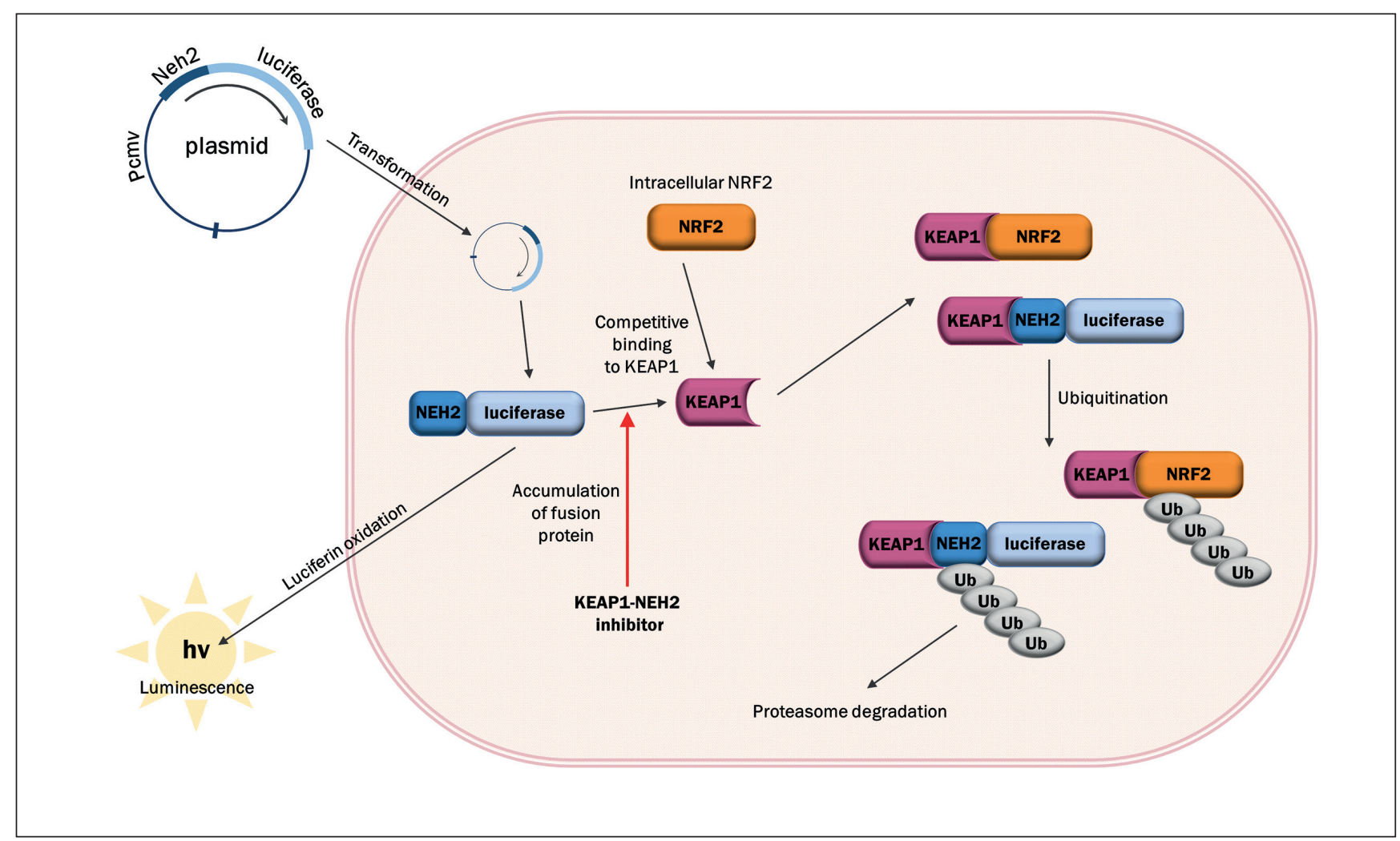

Fig. 3: Luciferase fusion reporter concept in the case of NRF2

cells natively fluoresce upon stimulation or under certain stress conditions, thus revealing specific information about the state of the cell. Optical interrogation of the hepatocyte culture with integrated "sensor" cells engineered to respond to particular signals may provide a way to extract this type of information in a real-time format.

\section{Biochip compatible reporter assays}

One of the most important modern trends in drug discovery is the switch from the "one disease - one target" mentality to the understanding that diseases are driven by shifts in a homeostatic balance. Even the smallest of these changes may involve many interacting genes and proteins upstream and downstream of a malfunctioning element in a biological puzzle. Hence, the focus of the HTS efforts has also shifted toward a search for various modulators which exert their action either through fine-tuning various transcription factors, or by controlling epigenetics landscapes. Cell-based reporter-enabled biochips are ideally suited for the purpose of HTS for activators and inhibitors of transcription factors. Reporters with fluorescent labels are preferable for use on the liver-on-a-chip devices, since they permit monitoring of the reporter response in intact cells. However, the recent development of a cell-permeable reagent for Renilla luciferase (Lindberg et al., 2013) opens the possibility of measuring luminescence within the intact cells.
The choice of reporter constructs for transforming hepatocyte-like cell lines is wide (Tab. 1). In particular, classic promoter-based reporters comprised of a fluorescent or luminescent protein gene under the promoter of a gene of interest, are readily available from commercial sources. Such promoter-based reporters are useful for monitoring of expression, and have been recently employed to monitor activation of CYP genes in HepG2 and HepaRG cells (Tsuji et al., 2014). The chief disadvantage of these reporters is their relatively low level of signal, which is often detected with a substantial delay due to the time necessary for promoter activation, transcription and translation of the reporter protein. Another problem is that many genes require for proper expression either relatively large promoter regions or even the presence of distant enhancers, which cannot be spliced into the plasmid- or virus-based reporter construct due to size limitation. This limitation could be surmounted by using bacterial artificial chromosome (BAC) transgene-based cell lines with very large, locus-wide holding capacity inclusive to all regulatory elements ensuring the normal physiological regulation of a fluorescent or luciferase reporter expression (Poser et al., 2008). The Bscl2-GFP and Srxn1-GFP BAC reporter assays were successfully employed to differentiate between two different types of response to genotoxic agents in many stably transfected cell lines (Hendriks et al., 2012). Recently, the feasibility of the BAC-reporter approach has been evaluated by testing the effect of over 2000 FDA approved drugs and active natural product compounds on the modulation of the Srxn1-GFP reporter in 
HepG2 cells (Wink et al., 2014). Integration of BAC-reporters into the cell component of the liver-on-a-chip devices is expected in the nearest future. The most current panel of BAC-GFP modified HepG2 cells, each complete with an upstream sensor, downstream transcription factor and their respective target gene, include reporters for the oxidative stress response pathway (Keap1/Nrf2/Srxn1), the unfolded protein response in the endoplasmic reticulum (Xbp1/Atf4/BiP/Chop), and the DNA damage response (53bp1/p53/p21) (Wink et al., 2017).

Another way to overcome the size limitation obstacle is to use a fusion-based reporter, which, typically, is comprised of either fluorescent or luminescent protein label enjoined with a full-size protein of interest expressed under a constitutive promoter, for example, $p_{\mathrm{cmv}}$. These reporters permit monitoring the half-life and the trafficking of the protein in the living cell. The overwhelming problem with these types of reporters is that the fused protein is fully physiologically active and is often capable of disturbing the intracellular balance, thus triggering an expression of the downstream genes and significantly shifting the transcriptomic and proteomic profile of the cells. In turn, these shifts reflect upon the efficacy and toxicity profiles obtained for the drugs under study. Another drawback of the fusion systems is that the promoter is constitutively active, often leading to overexpression of the construct over the physiological limits and resultant perturbation of cell homeostasis.

Yet another type of reporter has been developed for the monitoring of transcription factors regulated by ubiquitination and proteasomal degradation. The concept for these reporters is shown in Figure 3. In a nutshell, it is a fusion where a luminescent or fluorescent label is added to an isolated ubiquitination machinery recognition domain instead of a complete target protein. As the recognition domain has no affinity for DNA, it does not activate the specific program regulated by a particular transcription factor, even when overexpressed. There is still a possibility that overexpression of the recognition domain may serve as a decoy for ubiquitination machinery, hence, to at least some degree, stabilizing the endogenously expressed transcription factor, but these effects are usually negligible.

Among transcription factors regulated by ubiquitination and proteasomal degradation, there are three which are directly relevant to monitoring performance of hepatocytes embedded into liver-on-a-chip devices. These are the transcription factors $\mathrm{Nrf} 2$,

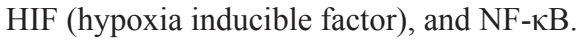

\subsection{Nrf2}

Nrf2 (nuclear factor erythroid 2-related factor 2) orchestrates the antioxidant response by inducing the expression of cytoprotective, pro-survival proteins such as thioredoxin reductase, glutathione reductase, glutathione S-transferase (GST), hemeoxygenase-1 (HO1), catalase and others. Under homeostatic conditions, Nrf2 is sequestered by binding to its inhibitory protein, Keap1 (Kelch-like ECH-associated protein-1). Keap1 serves as a bridge between Nrf2 and the Cul3-Rbx1 E3 ubiquitin ligase, which permits polyubiquitination of the lysines positioned within the central $\alpha$-helix of the Neh2 recognition domain. As a result of oxidative/electrophilic stress, active cysteines of Keap1 are mod- ified, and Nrf2 protein is released for subsequent translocation to the nucleus, where it induces expression from the promoters with the antioxidant response elements (ARE) (Kaspar et al., 2009).

Importantly, Nrf2 is constitutively active in many primary tumors (de la Vega et al., 2016). Hence, it is not surprising that tumor-derived HepG2 and HepaRG cells overexpress Nrf2-regulated genes. Upcyte ${ }^{\circledR}$ cultures do that too, however, to a lesser degree (Sison-Young et al., 2015). When HepaRG were compared to upcyte ${ }^{\circledR}$ cells, peroxiredoxin-1 and -2 , thioredoxin reductase and thioredoxin were found to be overexpressed substantially (Sison-Young et al., 2015), indicating that HepaRG cells are protected against effects of the drugs causing glutathione depletion. In other words, drug toxicity estimates obtained while working with HepaRG or HepG2 tend to be a bit more optimistic than they should be.

A reporter for monitoring Nrf2 activation, Neh2-luc (Smirnova et al., 2011), permits the real time monitoring right after addition, with no lag-period, while being 10 -fold more sensitive than ARE-luc reporters (Smirnova et al., 2011). This reporter has already found its use in the discovery labs, especially when an estimate of the intracellular alkylating power of a drug is needed. Neh2-luc enabled screening of drug libraries showed that at least $10 \%$ of all compounds behave as non-specific Nrf2 activators, meaning that they may alkylate active protein and peptide thiols in general, and glutathione in particular. In other words, administration of these drugs actively shifts the cellular redox balance and triggers the adaptive response. It is expected that Neh2-derived reporter will be fitted with a fluorescent label compatible with liver-on-a-chip devices.

\subsection{HIF}

HIF, a transcription factor capable of activating a battery of genes involved in glucose uptake and metabolism, extracellular $\mathrm{pH}$ control, angiogenesis, erythropoiesis, mitogenesis, and apoptosis, is expressed ubiquitously. It consists of 2 subunits, known as HIF $1-\alpha$ and HIF $1-\beta$. The levels of HIF $1-\alpha$ are regulated by hydroxylation of its Pro564 and/or 402 residues. This modification serves as a prerequisite for interaction with the tumor suppressor von Hippel-Lindau (VHL) protein, yielding a complex that provides for a rapid HIF ubiquitination and degradation (see review (Kaelin, 2005) and references therein). HIF hydroxylation is executed by the so-called HIF prolyl hydroxylases represented by 3 isozymes. Upregulation of HIF is an indication of the low oxygen supply and the enactment of the Warburg effect, a metabolic shift towards glycolysis.

A luc-reporter with ODD (oxygen degradable domain) of HIF has been developed (Safran et al., 2006) and its variant with Renilla luciferase has just become commercially available from Promega. In HTS, employment of HIF1 ODD-luc reporter allowed an identification of the hit with excellent neuroprotective properties later confirmed in hemorrhagic stroke models in vivo (Smirnova et al., 2010; Karuppagounder et al., 2016). Such a reporter might also be utilized for evaluation of substrate specificity of HIF prolyl hydroxylase isoforms and structure-activity relationship studies (Osipyants et al., 2017; Poloznikov et al., 2017; Smirnova et al., 2017). This fact clearly demonstrates 
superior properties of novel generation of cell-based reporters with respect to drug development. In liver-on-a-chip devices, in addition to drug discovery purposes, the reporter can be used to quantitate hypoxia and HIF activation. In hypoxia (or with HIF1 activation by other means), expression of cytochromes P450 and Phase II enzymes is down-regulated. This metabolic feature principally affects drug toxicity profiles; this is especially true for drugs developed for oncological treatment. Under hypoxia, HepaRG cells have been shown to display metabolic changes similar to those observed in poorly differentiated hepatocarcinomas; therefore, these cells may serve as a suitable in vitro model for testing of anticancer agents in hypoxic versus normoxic conditions (Legendre et al., 2009).

\subsection{NF- $\kappa B$}

$\mathrm{NF}-\kappa \mathrm{B}$ (nuclear factor kappa-light-chain-enhancer of activated $\mathrm{B}$ cells) controls both the inflammatory cytokine production and the survival of cells. In an inactive state, $\mathrm{NF}-\kappa \mathrm{B}$ is complexed with the inhibitory protein $I \kappa B \alpha$. Activation of I $\mathrm{B}$ kinase (IKK) results in phosphorylation of $\mathrm{I} \kappa \mathrm{B} \alpha$ protein, and its subsequent ubiquitination, which leads to dissociation of $\mathrm{I} \kappa \mathrm{B} \alpha$ from NF- $\kappa \mathrm{B}$ and eventual degradation of $\mathrm{I} \kappa \mathrm{B} \alpha$ by the proteasome. The activated NF- $\kappa \mathrm{B}$ is then translocated into the nucleus. Inhibiting $N F-\kappa B$ signaling has a potential for the treatment of cancers and inflammatory diseases. Importantly, persistant activation of NF- $\kappa \mathrm{B}$, which is known as chronic inflammation, is known to be a component of idiosyncratic hepatotoxicity (Jiang et al., 2017). Currently, there is no cell-based reporter to monitor $\mathrm{NF}-\kappa \mathrm{B}$ activation directly. However, a reporter monitoring degradation of its inhibitory partner I $\kappa \mathrm{B} \alpha$ can be constructed under the same principle as Neh2- and HIF ODD-derived reporters. The I $\kappa \mathrm{B} \alpha$-derived reporter can be used for drug discovery and for assessing drug toxicity, similarly to other reporters of this kind, with a special value for studying idiosyncratic hepatotoxicity in assays of controllably activated NF- $\kappa$ B.

\section{In silico modelling of liver function}

There has been significant progress in developing the liver-ona-chip and other liver-emulating technologies. However, the field is still somewhat in its infancy in terms of the standards, procedures and methods for translating the data obtained in vitro into reliable predictions applicable to human body responses. In parallel to various in vitro efforts, the development of predictive computational models of hepatic metabolism is also under way. Although many models perform quite well on the datasets they were developed on, they sometimes suffer from low statistical performance, with imbalanced sensitivity $v s$ specificity ratios.

Speaking generally, the predictive power of any computational model heavily depends on the quality of the respective training data set. When machine learning approaches are used, bigger datasets are preferable to smaller ones. The frameworks of large-scale screening programs, e.g., Tox21, already allowed the development of prediction models with an accuracy as high as $86.9 \%$, sensitivity of $82.5 \%$, and specificity of $92.9 \%$
(Capuzzi et al., 2016; Chen et al., 2012). On the other hand, the larger the dataset is, the higher the chance of mislabeling either the chemical structures or their toxicity classes. Consequently, manual trimming of large datasets may lead to improvement of model precision. To expand availability of highly confident data, industry-driven collaborative efforts are required. One example of such efforts is the eTOX project, which is comprised of a database filled with unpublished toxicology reports donated by 13 members of the pharmaceutical industry along with public toxicology data, and its customizable interface eTOXsys (Sanz et al., 2015). The models developed in the course of the eTOX project are available as possible augmentations for higher-level predictors. In one recent study, the models for BSEP, BCRP, P-glycoprotein and for OATP1B1 and 1B3 were investigated for their potential to improve the DILI-predicting algorithm. Surprisingly, in this particular case, an integration of the transporter-related data did not significantly improve the performance of the resultant model (Kotsampasakou et al., 2017).

There are some interesting attempts to model the liver "as a whole", with the homeostasis or the "starting state" of the liver being described by a set of differential equations, which can be modified as a reflection of the respective change observed under certain disease conditions and immunological states. This approach treats hepatotoxicity as a complex outcome of the factors at play, which includes the genotype of the patient, the drugs he or she is exposed to, and any underlying diseases, for example, steatosis. An example of this type of systemic model would be a VirtualLiver, developed by Strand Life Sciences, which couples equations describing the kinetics of biochemical pathways involved in liver homeostasis with those obtained after collection of a set of in vitro measurements quantifying various drug-induced perturbations (Subramanian et al., 2008). Clearly, this type of approach describes the biological system better than any endpoint analysis of toxicity, as it is able to reflect a steady accumulation of changes which eventually culminate in reaching an irreversible outcome. The development of holistic in silico models that simulate the metabolism of the liver is a necessary step towards an adequate and timely assessment of various chemical entities, natural or synthetic.

\section{Conclusion}

In this review, we describe the current approaches to develop liver-on-a-chip devices for the prediction of the liver toxicity in humans. These devices may include established immortal cell lines, for example, HepG2 - a "workhorse" of liver toxicology or its less malignant counterpart HepaRG, unmodified or modified primary human cells, and stem cell-derived hepatocyte-like cells, or iPSC. Like many technologies developing on the interface of applied biology and bioengineering, the liver-on-a-chip devices were started in an attempt to produce a "one-fits-all" solution, but eventually ended facing a variety of important dilemmas. In particular, the choice of biological material greatly influences both the performance of the devices and the precision of the toxicity reports. Unfortunately, unavoidable manipulations 
with the living component of the chip lead to activation of the $\mathrm{Nrf} 2$ and NF- $\mathrm{KB}$-dependent transcriptional programs, which, in turn, reflect upon the cellular response to environmental stressors. Among other impediments to the development of liver-on-achip technology are the problems with standardization of cells, limitations imposed by culturing, and the necessity to develop more complicated fluidic contours. Fortunately, recent breakthroughs in the development of cell-based reporters, including ones with fluorescent labels, permit monitoring the behavior of the cells embedded into the liver-on-a-chip devices. Finally, a set of computational approaches has been developed to model both toxic response pathways and the homeostasis of human liver as a whole; these approaches pave the way to enhance the in silico stage of assessment of potential toxicity.

\section{References}

Anson, B. D., Kolaja, K. L. and Kamp, T. J. (2011). Opportunities for use of human iPS cells in predictive toxicology. Clin Pharmacol Ther 89, 754-758. doi:10.1038/clpt.2011.9

Arakawa, H., Kamioka, H., Jomura, T. et al. (2017). Preliminary evaluation of three-dimensional primary human hepatocyte culture system for assay of drug-metabolizing enzyme-inducing potential. Biol Pharm Bull 40, 967-974. doi:10.1248/bpb. b16-00885

Baxter, M., Withey, S., Harrison, S. et al. (2015). Phenotypic and functional analyses show stem cell-derived hepatocyte-like cells better mimic fetal rather than adult hepatocytes. $J$ Hepatol 62, 581-589. doi:10.1016/j.jhep.2014.10.016

Bell, C. C., Hendriks, D. F., Moro, S. M. et al. (2016). Characterization of primary human hepatocyte spheroids as a model system for drug-induced liver injury, liver function and disease. Sci Rep 6, 25187. doi:10.1038/srep25187

Bell, C. C., Lauschke, V. M., Vorrink, S. U. et al. (2017). Transcriptional, functional, and mechanistic comparisons of stem cell-derived hepatocytes, HepaRG cells, and three-dimensional human hepatocyte spheroids as predictive in vitro systems for drug-induced liver injury. Drug Metab Dispos 45, 419429. doi:10.1124/dmd.116.074369

Bell, C. C., Dankers, A. C. A., Lauschke, V. M. et al. (2018). Comparison of hepatic 2D sandwich cultures and 3D spheroids for long-term toxicity applications: A multi-center study. Toxicol Sci 162, 655-666. doi:10.1093/toxsci/kfx289

Berger, B., Donzelli, M., Maseneni, S. et al. (2016). Comparison of liver cell models using the Basel phenotyping cocktail. Front Pharmacol 7, 443. doi:10.3389/fphar.2016.00443

Bogaards, J. J., Bertrand, M., Jackson, P. et al. (2000). Determining the best animal model for human cytochrome P450 activities: A comparison of mouse, rat, rabbit, dog, micropig, monkey and man. Xenobiotica 30, 1131-1152. doi:10.1080/00498250010021684

Brown, J. H., Das, P., DiVito, M. D. et al. (2018). Nanofibrous PLGA electrospun scaffolds modified with type I collagen influence hepatocyte function and support viability in vitro. Acta Biomater 73, 217-227. doi:10.1016/j.actbio.2018.02.009 Burkard, A., Dähn, C., Heinz, S. et al. (2012). Generation of proliferating human hepatocytes using Upcyte ${ }^{\circledR}$ technology: Characterisation and applications in induction and cytotoxicity assays. Xenobiotica 42, 939-956. doi:10.3109/00498254.2 012.675093

Cahan, P., Li, H., Morris, S. A. et al. (2014). CellNet: Network biology applied to stem cell engineering. Cell 158, 903-915. doi:10.1016/j.cell.2014.07.020

Capuzzi, S. J., Politi, R., Isayev, O. et al. (2016). QSAR modeling of Tox 21 challenge stress response and nuclear receptor signaling toxicity assays. Front Environ Sci 4, 3. doi:10.3389/ fenvs.2016.00003

Chan, H. F., Zhang, Y. and Leong, K. W. (2016). Efficient onestep production of microencapsulated hepatocyte spheroids with enhanced functions. Small 12, 2720-2730. doi:10.1002/ smll.201502932

Chaudhari, P., Prasad, N., Tian, L. and Jang, Y. Y. (2016). Determination of functional activity of human iPSC-derived hepatocytes by measurement of CYP metabolism. Methods Mol Biol 1357, 383-394. doi:10.1007/7651_2014_145

Chen, Y.-F., Tseng, C.-Y., Wang, H.-W. et al. (2012). Rapid generation of mature hepatocyte-like cells from human induced pluripotent stem cells by an efficient three-step protocol. Hepatology 55, 1193-1203. doi:10.1002/hep.24790

Chin, M. H., Mason, M. J., Xie, W. et al. (2009). Induced pluripotent stem cells and embryonic stem cells are distinguished by gene expression signatures. Cell Stem Cell 5, 111-123. doi:10.1016/j.stem.2009.06.008

Chiou, W. L. (1983). Mean hepatic transit time in the determination of mean absorption time. J Pharm Sci 72, 1365-1368. doi:10.1002/jps.2600721136

Chistiakov, D. A. and Chistiakov, P. A. (2012). Strategies to produce hepatocytes and hepatocyte-like cells from pluripotent stem cells. Hepatol Res 42, 111-119. doi:10.1111/j.1872034X.2011.00896.x

Choucha-Snouber, L., Aninat, C., Grsicom, L. et al. (2013). Investigation of ifosfamide nephrotoxicity induced in a liver-kidney co-culture biochip. Biotechnol Bioeng 110, $597-$ 608. doi:10.1002/bit.24707

Coussens, N. P., Braisted, J. C., Peryea, T. et al. (2017). Small-molecule screens: A gateway to cancer therapeutic agents with case studies of food and drug administration-approved drugs. Pharmacol Rev 69, 479-496. doi:10.1124/ pr.117.013755

de la Vega, M. R., Dodson, M., Chapman, E. and Zhang, D. D. (2016). NRF2-targeted therapeutics: New targets and modes of NRF2 regulation. Curr Opin Toxicol 1, 62-70. doi:10.1016/j. cotox.2016.10.005

Delvecchio, C., Tiefenbach, J. and Krause, H. M. (2011). The zebrafish: A powerful platform for in vivo, HTS drug discovery. Assay Drug Dev Technol 9, 354-361. doi:10.1089/ adt. 2010.0346

Endo, S., Toyoda, Y., Fukami, T. et al. (2012). Stimulation of human monocytic THP-1 cells by metabolic activation of hepatotoxic drugs. Drug Metab Pharmacokinet 27, 621-630. doi:10.2133/dmpk.DMPK-12-RG-019

García-Cañaveras, J. C., Castell, J. V., Donato, M. T. and Lahoz, 
A. (2016). A metabolomics cell-based approach for anticipating and investigating drug-induced liver injury. Sci Rep 6, 27239. doi:10.1038/srep27239

Gao, X. and Liu, Y. (2017). A transcriptomic study suggesting human iPSC-derived hepatocytes potentially offer a better in vitro model of hepatotoxicity than most hepatoma cell lines. Cell Biol Toxicol 33, 407-421. doi:10.1007/s10565-0179383-z

Gerets, H. H. J., Tilmant, K., Gerin, B. et al. (2012). Characterization of primary human hepatocytes, HepG2 cells, and HepaRG cells at the mRNA level and CYP activity in response to inducers and their predictivity for the detection of human hepatotoxins. Cell Biol Toxicol 28, 69-87. doi:10.1007/ s10565-011-9208-4

Goresky, C. A. (1963). A linear method for determining liver sinusoidal and extravascular volumes. Am J Physiol 204, 626640. doi:10.1152/ajplegacy.1963.204.4.626

Gripon, P., Rumin, S., Urban, S. et al. (2002). Infection of a human hepatoma cell line by hepatitis B virus. Proc Natl Acad Sci U S A 99, 15655-15660. doi:10.1073/pnas.232137699

Guillouzo, A., Corlu, A., Aninat, C. et al. (2007). The human hepatoma HepaRG cells: A highly differentiated model for studies of liver metabolism and toxicity of xenobiotics. Chem Biol Interact 168, 66-73. doi:10.1016/j.cbi.2006.12.003

Gunness, P., Mueller, D., Shevchenko, V. et al. (2013). 3D organotypic cultures of human HepaRG cells: A tool for in vitro toxicity studies. Toxicol Sci 133, 67-78. doi:10.1093/toxsci/ $\mathrm{kft} 021$

Hanioka, N., Isobe, T., Kinashi, Y. et al. (2016). Hepatic and intestinal glucuronidation of mono(2-ethylhexyl) phthalate, an active metabolite of di(2-ethylhexyl) phthalate, in humans, dogs, rats, and mice: An in vitro analysis using microsomal fractions. Arch Toxicol 90, 1651-1657. doi:10.1007/s00204015-1619-1

Hart, S. N., Li, Y., Nakamoto, K. et al. (2010). A comparison of whole genome gene expression profiles of HepaRG cells and HepG2 cells to primary human hepatocytes and human liver tissues. Drug Metab Dispos 38, 988-994. doi:10.1124/ dmd.109.031831

He, Q., Okajima, T., Onoe, H. et al. (2018). Origami-based self-folding of co-cultured NIH/3T3 and HepG2 cells into 3D microstructures. Sci Rep 14, 4556. doi:10.1038/s41598-01822598-x

Hendriks, G., Atallah, M., Morolli, B. et al. (2012). The ToxTracker assay: Novel GFP reporter systems that provide mechanistic insight into the genotoxic properties of chemicals. Toxicol Sci 125, 285-298. doi:10.1093/toxsci/kfr281

Herzog, N., Hansen, M., Miethbauer, S. et al. (2016). Primary-like human hepatocytes genetically engineered to obtain proliferation competence display hepatic differentiation characteristics in monolayer and organotypical spheroid cultures. Cell Biol Int 40, 341-353. doi:10.1002/cbin.10574

Huang, P., Zhang, L., Gao, Y. et al. (2014). Direct reprogramming of human fibroblasts to functional and expandable hepatocytes. Cell Stem Cell 14, 370-384. doi:10.1016/j. stem.2014.01.003

Hurrell, T., Ellero, A. A., Masso, Z. F. and Cromarty, A. D.
(2018). Characterization and reproducibility of HepG2 hanging drop spheroids toxicology in vitro. Toxicol In Vitro 21, 86-94. doi:10.1016/j.tiv.2018.02.013

Jiang, J., Mathijs, K., Timmermans, L. et al. (2017). Omics-based identification of the combined effects of idiosyncratic drugs and inflammatory cytokines on the development of drug-induced liver injury. Toxicol Appl Pharmacol 332, 100-108. doi:10.1016/j.taap.2017.07.014

Jossé, R., Aninat, C., Glaise, D. et al. (2008). Long-term functional stability of human HepaRG hepatocytes and use for chronic toxicity and genotoxicity studies. Drug Metab Dispos 36, 1111-1118. doi:10.1124/dmd.107.019901

Kaelin, W. G. (2005). Proline hydroxylation and gene expression. Annu Rev Biochem 74, 115-128. doi:10.1146/annurev. biochem.74.082803.133142

Karuppagounder, S. S., Alim, I., Khim, S. J. et al. (2016). Therapeutic targeting of oxygen-sensing prolyl hydroxylases abrogates ATF4-dependent neuronal death and improves outcomes after brain hemorrhage in several rodent models. Sci Transl Med 8, 328ra29. doi:10.1126/scitranslmed.aac6008

Kaspar, J. W., Niture, S. K. and Jaiswal, A. K. (2009). Nrf2: INrf2 (Keap1) signaling in oxidative stress. Free Radic Biol Med 47, 1304-1309. doi:10.1016/j.freeradbiomed.2009.07.035

Kaur, P. R., Mehta, R. G., Arora, S. and Singh, B. (2018). Progression of conventional hepatic cell culture models to bioengineered HepG2 cells for evaluation of herbal bioactivities. Biotechnol Lett 40, 881-893. doi:10.1007/s10529-018-2547-y.

Kegel, V., Pfeiffer, E., Burkhardt, B. et al. (2015). Subtoxic concentrations of hepatotoxic drugs lead to Kupffer cell activation in a human in vitro liver model: An approach to study DILI. Mediators Inflamm 2015, 640631. doi:10.1155/2015/640631

Kim, Y., Kang, K., Yoon, S. et al. (2018). Prolongation of liverspecific function for primary hepatocytes maintenance in $3 \mathrm{D}$ printed architectures. Organogenesis 14, 1-12. doi:10.1080/15 476278.2018.1423931

Klein, S., Mueller, D., Schevchenko, V. and Noor, F. (2014). Long-term maintenance of HepaRG cells in serum-free conditions and application in a repeated dose study. J Appl Toxicol 34, 1078-1086. doi:10.1002/jat.2929

Knöspel, F., Jacobs, F., Freyer, N. et al. (2016). In vitro model for hepatotoxicity studies based on primary human hepatocyte cultivation in a perfused 3D bioreactor system. Int J Mol Sci 17, 584. doi:10.3390/ijms17040584

Kostadinova, R., Boess, F., Applegate, D. et al. (2013). A longterm three dimensional liver co-culture system for improved prediction of clinically relevant drug-induced hepatotoxicity. Toxicol Appl Pharmacol 268, 1-16. doi:10.1016/j.taap. 2013.01.012

Kotsampasakou, E., Montanari, F. and Ecker, G. F. (2017). Predicting drug-induced liver injury: The importance of data curation. Toxicology 389, 139-145. doi:10.1016/j.tox.2017.06.003

Kratochwil, N. A., Meille, C., Fowler, S. et al. (2017). Metabolic profiling of human long-term liver models and hepatic clearance predictions from in vitro data using nonlinear mixed-effects modeling. AAPS J 19, 534-550. doi:10.1208/ s12248-016-0019-7

Langley, G., Austin, C. P., Balapure, A. K. et al. (2015). Les- 
sons from toxicology: Developing a $21^{\text {st }}$-century paradigm for medical research. Environ Health Perspect 123, A268-272. doi:10.1289/ehp. 1510345

Le Vee, M., Jigorel, E., Glaise, D. et al. (2006). Functional expression of sinusoidal and canalicular hepatic drug transporters in the differentiated human hepatoma HepaRG cell line. Eur J Pharm Sci 28, 109-117. doi:10.1016/j.ejps.2006.01.004

Le Vee, M., Noel, G., Jouan, E. et al. (2013). Polarized expression of drug transporters in differentiated human hepatoma HepaRG cells. Toxicol In Vitro 27, 1979-1986. doi:10.1016/j. tiv.2013.07.003

Le Vee, M., Jouan, E., Noel, G. et al. (2015). Polarized location of SLC and ABC drug transporters in monolayer-cultured human hepatocytes. Toxicol In Vitro 29, 938-946. doi:10.1016/j. tiv.2015.03.019

Legendre, C., Hori, T., Loyer, P. et al. (2009). Drug-metabolising enzymes are down-regulated by hypoxia in differentiated human hepatoma HepaRG cells: HIF-1alpha involvement in CYP3A4 repression. Eur $J$ Cancer 45, 2882-2892. doi: 10.1016/j.ejca.2009.07.010

Leite, S. B., Roosens, T., El Taghdouini, A. et al. (2016). Novel human hepatic organoid model enables testing of drug-induced liver fibrosis in vitro. Biomaterials 78, 1-10. doi:10.1016/j. biomaterials.2015.11.026

Levy, G., Bomze, D., Heinz, S. et al. (2015). Long-term culture and expansion of primary human hepatocytes. Nat Biotechnol 33, 1264-1271. doi:10.1038/nbt.3377

Liddle, C. and Stedman, C. (2007). Hepatic metabolism of drugs. In J. Rodes, J. Benhamou, A. Blei et al. (eds.), Text Book of Hepatology: From Basic Science to Clinical Practice (241249). $3^{\text {rd }}$ edition. Wiley-Blackwell.

Lindberg, E., Mizukami, S., Ibata, K. et al. (2013). Development of cell-impermeable coelenterazine derivatives. Chem Sci 4, 4395. doi:10.1039/c3sc51985f

Liu, H., Ye, Z., Kim, Y. et al. (2010). Generation of endoderm-derived human induced pluripotent stem cells from primary hepatocytes. Hepatology 51, 1810-1819. doi:10.1002/hep.23626

Lübberstedt, M., Müller-Vieira, U., Mayer, M. et al. (2011). HepaRG human hepatic cell line utility as a surrogate for primary human hepatocytes in drug metabolism assessment in vitro. J Pharmacol Toxicol Methods 63, 59-68. doi:10.1016/j. vascn.2010.04.013

Luttringer, O., Theil, F. P., Lavé, T. et al. (2002). Influence of isolation procedure, extracellular matrix and dexamethasone on the regulation of membrane transporters gene expression in rat hepatocytes. Biochem Pharmacol 64, 1637-1650. doi:10.1016/S0006-2952(02)01382-5

Lynch, T. and Price, A. (2007). The effect of cytochrome P450 metabolism on drug response, interactions, and adverse effects. Am Fam Physician 76, 391-396.

Makarova, J. A., Maltseva, D. V, Galatenko, V. V et al. (2014). Exercise immunology meets MiRNAs. Exerc Immunol Rev 20, 135-164.

Makarova, J. A., Shkurnikov, M. U., Wicklein, D. et al. (2016). Intracellular and extracellular microRNA: An update on lo- calization and biological role. Prog Histochem Cytochem 51, 33-49. doi:10.1016/j.proghi.2016.06.001

Marchetto, M. C., Yeo, G. W., Kainohana, O. et al. (2009). Transcriptional signature and memory retention of human-induced pluripotent stem cells. PLoS One 4, e7076. doi:10.1371/ journal.pone.0007076

Marx, U., Andersson, T. B., Bahinski, A. et al. (2016). Biology-inspired microphysiological system approaches to solve the prediction dilemma of substance testing. ALTEX 33, 272321. doi:10.14573/altex.1603161

Materne, E.-M., Ramme, A. P., Terrasso, A. P. et al. (2015). A multi-organ chip co-culture of neurospheres and liver equivalents for long-term substance testing. J Biotechnol 205, 36-46. doi:10.1016/j.jbiotec.2015.02.002

Miller, M. G., Beyer, J., Hall, G. L. et al. (1993). Predictive value of liver slices for metabolism and toxicity in vivo: Use of acetaminophen as a model hepatotoxicant. Toxicol Appl Pharmacol 122, 108-116. doi:10.1006/taap.1993.1178

Miura, K., Okada, Y., Aoi, T. et al. (2009). Variation in the safety of induced pluripotent stem cell lines. Nat Biotechnol 27, 743745. doi:10.1038/nbt.1554

Mohri, T., Nakajima, M., Fukami, T. et al. (2010). Human CYP2E1 is regulated by miR-378. Biochem Pharmacol 79, 1045-1052. doi:10.1016/j.bcp.2009.11.015

Nickischer, D., Elkin, L., Cloutier, N. et al. (2018). Challenges and opportunities in enabling high-throughput, miniaturized high content screening. Methods Mol Biol 1683, 165-191. doi:10.1007/978-1-4939-7357-6 11

Noel, G., Le Vee, M., Moreau, A. et al. (2013). Functional expression and regulation of drug transporters in monolayer- and sandwich-cultured mouse hepatocytes. Eur J Pharm Sci 49, 39-50. doi:10.1016/j.ejps.2013.01.013

O’Reilly, L. P., Luke, C. J., Perlmutter, D. H. et al. (2014). C. elegans in high-throughput drug discovery. Adv Drug Deliv Rev 69-70, 247-53. doi:10.1016/j.addr.2013.12.001

Okamoto, M., Ishida, Y., Keogh, A. and Strain, A. (1998). Evaluation of the function of primary human hepatocytes cocultured with the human hepatic stellate cell (HSC) line LI90. Int $J$ Artif Organs 21, 353-359. doi:10.1177/039139889802100607

Olson, H., Betton, G., Robinson, D. et al. (2000). Concordance of the toxicity of pharmaceuticals in humans and in animals. Regul Toxicol Pharmacol 32, 56-67. doi:10.1006/rtph.2000. 1399

Osipyants, A. I., Smirnova, N. A., Khristichenko, A. Y. et al. (2017). Enzyme-substrate reporters for evaluation of substrate specificity of HIF prolyl hydroxylase isoforms. Biochemistry (Mosc) 82, 1207-1214. doi:10.1134/S0006297917100145

Paech, F., Mingard, C., Grünig, D. et al. (2018). Mechanisms of mitochondrial toxicity of the kinase inhibitors ponatinib, regorafenib and sorafenib in human hepatic HepG2 cells. Toxicology 15, 34-44. doi:10.1016/j.tox.2018.01.005

Paemanee, A., Sornjai, W., Kittisenachai, S. et al. (2017). Nevirapine induced mitochondrial dysfunction in HepG2 cells. Sci Rep 23, 9194. doi:10.1038/s41598-017-09321-y

Pandey, U. B. and Nichols, C. D. (2011). Human disease models 
in Drosophila melanogaster and the role of the fly in therapeutic drug discovery. Pharmacol Rev 63, 411-436. doi:10.1124/ pr.110.003293

Pedersen, J. F., Larsen, V. A., Bytzer, P. et al. (2005). Hepatic transit time of ultrasound contrast in biopsy characterized liver disease. Acta Radiol 46, 557-560. doi:10.1080/02841850510021689

Peters, T. S. (2005). Do preclinical testing strategies help predict human hepatotoxic potentials? Toxicol Pathol 33, 146-154. doi:10.1080/01926230590522121

Poloznikov, A. A., Zakhariants, A. A., Nikulin, S. V. et al. (2017). Structure-activity relationship for branched oxyquinoline HIF activators: Effect of modifications to phenylacetamide "tail". Biochimie 133, 74-79. doi:10.1016/j.biochi.2016.12.004

Poser, I., Sarov, M., Hutchins, J. R. et al. (2008). BAC TransgeneOmics: A high-throughput method for exploration of protein function in mammals. Nat Methods 5, 409-415. doi:10.1038/nmeth.1199

Radley, A. H., Schwab, R. M., Tan, Y. et al. (2017). Assessment of engineered cells using CellNet and RNA-seq. Nat Protoc 12, 1089-1102. doi:10.1038/nprot.2017.022

Ramachandran, S. D., Schirmer, K., Münst, B. et al. (2015a). In vitro generation of functional liver organoid-like structures using adult human cells. PLoS One 10, e0139345. doi:10.1371/ journal.pone.0139345

Ramachandran, S. D., Vivarès, A., Klieber, S. et al. (2015b). Applicability of second-generation upcyte ${ }^{\circledR}$ human hepatocytes for use in CYP inhibition and induction studies. Pharmacol Res Perspect 3, e00161. doi:10.1002/prp2.161

Ramirez, T., Strigun, A., Verlohner. A. et al. (2018). Prediction of liver toxicity and mode of action using metabolomics in vitro in HepG2 cells. Arch Toxicol 92, 893-906. doi:10.1007/ s00204-017-2079-6

Raucy, J. L. and Lasker, J. M. (2010). Current in vitro high throughput screening approaches to assess nuclear receptor activation. Curr Drug Metab 11, 806-814. doi:10.2174/138920010794328896

Ries, K., Krause, P., Solsbacher, M. et al. (2000). Elevated expression of hormone-regulated rat hepatocyte functions in a new serum-free hepatocyte-stromal cell coculture model. In Vitro Cell Dev Biol Anim 36, 502-512. doi:10.1290/1071-269 0(2000)036<0502:EEOHRR $>2.0 . \mathrm{CO} ; 2$

Rodríguez-Antona, C., Donato, M. T., Boobis, A. et al. (2002). Cytochrome P450 expression in human hepatocytes and hepatoma cell lines: Molecular mechanisms that determine lower expression in cultured cells. Xenobiotica 32, 505-520. doi:10.1080/00498250210128675

Safran, M., Kim, W. Y., O’Connell, F. et al. (2006). Mouse model for noninvasive imaging of HIF prolyl hydroxylase activity: Assessment of an oral agent that stimulates erythropoietin production. Proc Natl Acad Sci U S A 103, 105-110. doi:10.1073/ pnas.0509459103

Salerno, S., Campana, C., Morelli, S. et al. (2011). Human hepatocytes and endothelial cells in organotypic membrane systems. Biomaterials 32, 8848-8859. doi:10.1016/j.bio materials.2011.08.004
Sanz, F., Carrió, P., López, O. et al. (2015). Integrative modeling strategies for predicting drug toxicities at the eTOX project. Mol Inform 34, 477-484. doi:10.1002/minf.201400193

Schaefer, M., Schänzle, G., Bischoff, D. and Süssmuth, R. D. (2016). Upcyte human hepatocytes: A potent in vitro tool for the prediction of hepatic clearance of metabolically stable compounds. Drug Metab Dispos 44, 435-444. doi:10.1124/ dmd.115.067348

Schaefer, M., Morinaga, G., Matsui, A. et al. (2018). Quantitative expression of hepatobiliary transporters and functional uptake of substrates in hepatic two-dimensional sandwich cultures: A comparative evaluation of upcyte and primary human hepatocytes. Drug Metab Dispos 46, 166-177. doi:10.1124/ dmd.117.078238

Schwartz, R. E., Fleming, H. E., Khetani, S. R. and Bhatia, S. N. (2014). Pluripotent stem cell-derived hepatocyte-like cells. Biotechnol Adv 32, 504-513. doi:10.1016/j.biotechadv. 2014.01.003

Semenova, O. V., Petrov, V. A., Gerasimenko, T. N. et al. (2016). Effect of circulation parameters on functional status of HepaRG spheroids cultured in microbioreactor. Bull Exp Biol Med 161, 425-429 doi:10.1007/s10517-016-3430-2

Shafritz, D., Oertel, M., Dabeva, M. and Grompe, M. (2009). Liver repopulation by cell transplantation and the role of stem cells. In I. M. Arias, J. Boyer, D. Cohen et al. (eds.), The Liver: Biology and Pathobiology. $5^{\text {th }}$ edition. Chichester, UK: John Wiley \& Sons, Ltd. doi:10.1002/9780470747919

Shah, U. K., Mallia, J. O., Singh, N. et al. (2018). A threedimensional in vitro HepG2 cells liver spheroid model for genotoxicity studies. Mutat Res 825, 51-58. doi:10.1016/j. mrgentox.2017.12.005

Shulman, M. and Nahmias, Y. (2013). Long-term culture and coculture of primary rat and human hepatocytes. Methods $\mathrm{Mol}$ Biol 945, 287-302. doi:10.1007/978-1-62703-125-7_17

Si-Tayeb, K., Noto, F. K., Nagaoka, M. et al. (2010). Highly efficient generation of human hepatocyte-like cells from induced pluripotent stem cells. Hepatology 51, 297-305. doi:10.1002/ hep. 23354

Sison-Young, R. L., Mitsa, D., Jenkins, R. E. et al. (2015). Comparative proteomic characterization of 4 human liver-derived single cell culture models reveals significant variation in the capacity for drug disposition, bioactivation, and detoxication. Toxicol Sci 147, 412-424. doi:10.1093/toxsci/kfv136

Smirnova, N. A., Rakhman, I., Moroz, N. et al. (2010). Utilization of an in vivo reporter for high throughput identification of branched small molecule regulators of hypoxic adaptation. Chem Biol 17, 380-391. doi:10.1016/j.chembiol.2010.03.008

Smirnova, N. A., Haskew-Layton, R. E., Basso, M. et al. (2011). Development of Neh2-luciferase reporter and its application for high throughput screening and real-time monitoring of Nrf2 activators. Chem Biol 18, 752-765. doi:10.1016/j.chembiol. 2011.03.013

Smirnova, N. A., Kaidery, N. A., Hushpulian, D. M. et al. (2017). Bioactive flavonoids and catechols as Hif1 and Nrf2 protein stabilizers - Implications for Parkinson's disease. Aging Dis 8, 1-18. doi:10.14336/AD.2016.0505 
Song, Z., Cai, J., Liu, Y. et al. (2009). Efficient generation of hepatocyte-like cells from human induced pluripotent stem cells. Cell Res 19, 1233-1242. doi:10.1038/cr.2009.107

Soto-Gutierrez, A., Navarro-Alvarez, N., Yagi, H. et al. (2010). Engineering of an hepatic organoid to develop liver assist devices. Cell Transplant 19, 815-822. doi:10. 3727/096368910X508933

Subramanian, K., Raghavan, S., Rajan Bhat, A. et al. (2008). A systems biology based integrative framework to enhance the predictivity of in vitro methods for drug-induced liver injury. Expert Opin Drug Saf 7, 647-662. doi:10.1517/ 14740330802501211

Swift, B., Pfeifer, N. D. and Brouwer, K. L. (2010). Sandwich-cultured hepatocytes: An in vitro model to evaluate hepatobiliary transporter-based drug interactions and hepatotoxicity. Drug Metab Rev 42, 446-471. doi:10.3109/03602530903491881

Takahashi, K. and Yamanaka, S. (2006). Induction of pluripotent stem cells from mouse embryonic and adult fibroblast cultures by defined factors. Cell 126, 663-676. doi:10.1016/j. cell.2006.07.024

Takayama, K., Inamura, M., Kawabata, K. et al. (2012). Efficient generation of functional hepatocytes from human embryonic stem cells and induced pluripotent stem cells by HNF4 $\alpha$ transduction. Mol Ther 20, 127-137. doi:10.1038/mt.2011.234

Tehranirokh, M., Kouzani, A. Z., Francis, P. S. and Kanwar, J. R. (2013). Microfluidic devices for cell cultivation and proliferation. Biomicrofluidics 7, 51502. doi:10.1063/1.4826935

Tsuji, S., Kawamura, F., Kubiura, M. et al. (2014). Dual-color fluorescence imaging to monitor CYP3A4 and CYP3A7 expression in human hepatic carcinoma HepG2 and HepaRG cells. PLoS One 9, e104123. doi:10.1371/journal.pone.0104123

Turchinovich, A., Tonevitsky, A. G., Cho, W. C. and Burwinkel, B. (2015). Check and mate to exosomal extracellular miRNA: New lesson from a new approach. Front Mol Biosci 2, 11. doi:10.3389/fmolb.2015.00011

Turchinovich, A., Tonevitsky, A. G. and Burwinkel, B. (2016). Extracellular miRNA: A collision of two paradigms. Trends Biochem Sci 41, 883-892. doi:10.1016/j.tibs.2016.08.004

Wagner, I., Materne, E.-M., Brincker, S. et al. (2013). A dynamic multi-organ-chip for long-term cultivation and substance testing proven by $3 \mathrm{D}$ human liver and skin tissue co-culture. $\mathrm{Lab}$ Chip 13, 3538. doi:10.1039/c31c50234a

Ware, B. R., Berger, D. R. and Khetani, S. R. (2015). Prediction of drug-induced liver injury in micropatterned co-cultures containing iPSC-derived human hepatocytes. Toxicol Sci 145, 252-262. doi:10.1093/toxsci/kfv048

Wilkening, S., Stahl, F. and Bader, A. (2003). Comparison of primary human hepatocytes and hepatoma cell line Hepg2 with regard to their biotransformation properties. Drug Metab Dispos 31, 1035-1042. doi:10.1124/dmd.31.8.1035

Wink, S., Hiemstra, S., Huppelschoten, S. et al. (2014). Quantitative high content imaging of cellular adaptive stress response pathways in toxicity for chemical safety assessment. Chem Res Toxicol 27, 338-355. doi:10.1021/tx4004038

Wink, S., Hiemstra, S., Herpers, B. and van de Water, B. (2017). High-content imaging-based BAC-GFP toxicity pathway reporters to assess chemical adversity liabilities. Arch Toxicol 91, 1367-1383. doi:10.1007/s00204-016-1781-0

Xia, X. and Wong, S. T. (2012). Concise review: A high-content screening approach to stem cell research and drug discovery. Stem Cells 30, 1800-1807. doi:10.1002/stem.1168

Yamada, M., Hori, A., Sugaya, S. et al. (2015). Cell-sized condensed collagen microparticles for preparing microengineered composite spheroids of primary hepatocytes. Lab Chip 15, 3941-3951. doi:10.1039/c51c00785b

Yan, X., Wang, J., Zhu, L. et al. (2015). A ready-to-use, versatile, multiplex-able three-dimensional scaffold-based immunoassay chip for high throughput hepatotoxicity evaluation. Lab Chip 15, 2634-2646. doi:10.1039/c5lc00313j

Zakhariants, A. A., Burmistrova, O. A., Shkurnikov, M. Y. et al. (2016). Development of a specific substrate-inhibitor panel (liver-on-a-chip) for evaluation of cytochrome P450 activity. Bull Exp Biol Med 162, 170-174. doi:10.1007/s10517-0163567-z

\section{Conflict of interest}

The authors declare no conflicts of interest.

\section{Acknowledgements}

The work was supported by the Russian Science Foundation (grant No. 16-14-10226 and grant 16-15-00290) and the Scientific State Program 6.9899.2017/8.9, Russia. The authors would like to thank Udo Schumacher and Dimitry Spitkovsky for critical review of the article. 